\title{
Quantitative Depth Profiling of Argon in Tungsten Films by Secondary Ion Mass Spectrometry
}

\author{
Hideyuki YAMAZAKI
}

Toshiba Corporation, Research and Development Center, 8 Shinsugita-cho, Isogo, Yokohama 235-8522, Japan

\begin{abstract}
Depth profiling of Ar in Ar-implanted tungsten (W) films with an excellent detection limit was investigated by secondary ion mass spectrometry (SIMS). Depth profiles of $\mathrm{Ar}$ with the detection of $\mathrm{Ar}^{+}$and $\mathrm{ArCs}^{+}$secondary ions, which were produced by $\mathrm{O}_{2}^{+}$and $\mathrm{Cs}^{+}$primary ions, respectively, were compared in view of the detection limit and the depth resolution. The detection limit of $\mathrm{Ar}$ monitoring $\mathrm{Ar}^{+}$was limited by the carbon- and oxygen-containing molecular ion $\left(\mathrm{C}_{2} \mathrm{O}^{+}\right)$in the sample as well as in the SIMS instrument. It was observed that some of the $\mathrm{Ar}^{+}$ions were produced in the vacuum above the sample surfaces, whereas the ionization of almost all $\mathrm{C}_{2} \mathrm{O}^{+}$occurred at the samples. By using different energy spectra between $\mathrm{Ar}^{+}$and $\mathrm{C}_{2} \mathrm{O}^{+}$, we showed that the energy-filtering technique is advantageous for suppressing $\mathrm{C}_{2} \mathrm{O}^{+}$ion detection. It is also confirmed that the $\mathrm{ArCs}^{+}$secondary ion is only slighting by the $\mathrm{C}_{2} \mathrm{OCs}^{+}$mass-interference ion. A detection limit of $4 \times 10^{18} \mathrm{~cm}^{-3}$ for monitoring $\mathrm{Ar}^{+}$and $3 \times 10^{16} \mathrm{~cm}^{-3}$ for monitoring $\mathrm{ArCs}^{+}$was achieved under a primary-ion current density of $0.16 \mathrm{~mA} / \mathrm{cm}^{2}$. The detection of $\mathrm{ArCs}^{+}$ion rather than $\mathrm{Ar}^{+}$was found to be superior in the detection limit and the depth resolution. We conclude that SIMS is useful for the determination of the Ar depth distribution in $\mathrm{W}$ films.
\end{abstract}

(Received September 22, 2000; Accepted November 20, 2000)

\section{Introduction}

Rare gases are universally used as working gases of DC, RF, magnetron and ion beam sputtering sources. Therefore, rare gas species are incorporated unintentionally in films during growth by sputter deposition. The increase in the amount of trapped rare gas species leads to a change in the structure and electrical properties of the film. For example, the compressive stress in sputter-deposited $\mathrm{TiC}^{1}$ and $\mathrm{Mo}^{2}$ films is related to the trapped argon concentration in the films. The resistivities of silver and tungsten films increase in proportion to the incorporated argon concentration. ${ }^{3}$

Secondary ion mass spectrometry (SIMS) has been widely used to characterize trace elements in thin films and solid surfaces due to its high detection power and large dynamic range for surface-distribution analysis..$^{4-7}$ However, the ionization probability of secondary ions mainly depends on three factors: ${ }^{8-12}$ (i) the atom's ionization potential (IP) for measuring positive secondary ions, (ii) the atom's electron affinity (EA) for measuring negative secondary ions and (iii) the surface work function. Thus, it is difficult to achieve lower detection limits of the rare gas species because of their high IP $(12.13-24.59 \mathrm{eV})$ and low EA $(0 \mathrm{eV}) .{ }^{13}$ The earliest report on depth profiles for He implanted in $\mathrm{Si}$ and GaAs was by Wilson, Deline and Hopkins, ${ }^{14}$ who demonstrated that $\mathrm{He}$ densities greater than about $10^{18} \mathrm{~cm}^{-3}$ could be measured by an oxygen primary ion beam. It was noted that detecting $\mathrm{MCs}^{+}(\mathrm{M}$ is the element to be analyzed) secondary ions formed under the bombardment of $\mathrm{Cs}^{+}$primary ions can be applied to a SIMS analysis of the rare gases. Ray and co-workers ${ }^{15}$ have shown the detection limits for $\mathrm{Ar}$ and $\mathrm{Kr}$ in $\mathrm{Si}, \mathrm{Ge}$ and $\mathrm{GaAs}$ using $\mathrm{Cs}^{+}$ (or $\mathrm{O}_{2}{ }^{+}$) primary ions and monitoring $\mathrm{ArCs}^{+}\left(\right.$or $\mathrm{Ar}^{+}$) secondary ions. Gnaser and Oechsner ${ }^{16}$ investigated the He depth profile in $\mathrm{Si}$ by SIMS and monitored $\mathrm{HeCs}^{+}$secondary ions. The detection limits of $\mathrm{He}, \mathrm{Ar}$ and $\mathrm{Kr}$ measured by various authors are summarized in Table 1. As mentioned above, the properties of sputter-deposited films are related to the amount of $\mathrm{Ar}$ present in the films. Therefore, it is important to determine the depth profile of Ar with a lower detection limit. To the author's knowledge, there are no experimental data on the SIMS detection limit of Ar in tungsten (W).

In this paper, we report on the depth profiling of $\mathrm{Ar}$ in $\mathrm{W}$ films with monitoring $\mathrm{Ar}^{+}$and $\mathrm{ArCs}^{+}$secondary ions. First, the influence of secondary ion's kinetic energy filtering on the detection limit of Ar was evaluated in order to resolve the massinterference ion. We also investigated the detection limits of $\mathrm{Ar}$ in $\mathrm{W}$ as a function of the primary-ion current density. Next, the depth resolutions of Ar profiles monitoring $\mathrm{Ar}^{+}$and $\mathrm{ArCs}^{+}$were compared.

\section{Experimental}

The samples used were ${ }^{40} \mathrm{Ar}$ implanted and non-implanted tungsten (W) films deposited on silicon wafers by a sputtering technique. In order to remove native oxide and organic contaminants, silicon wafers were chemically cleaned prior to the deposition of $\mathrm{W}$ films. $\mathrm{W}$ films (450 nm thick) were deposited by ion-beam sputtering with Xe sputtering gas at room temperature. The implant energy and dose of ${ }^{40} \mathrm{Ar}$ were $100 \mathrm{keV}$ and $5 \times 10^{15} \mathrm{~cm}^{-2}$, respectively.

All SIMS experiments were performed on a Cameca IMS-4f instrument using either $\mathrm{O}_{2}{ }^{+}$or $\mathrm{Cs}^{+}$primary ions. The $\mathrm{O}_{2}{ }^{+}$and $\mathrm{Cs}^{+}$primary ion beams were accelerated to $10 \mathrm{kV}$. The sample holder was biased to normal $+4.5 \mathrm{kV}$ in order to eject positive secondary ions. Therefore, the primary ion beams reach the sample surface with an impact energy of $5.5 \mathrm{keV}$. The sample 
Table 1 SIMS detection limits of rare gases

\begin{tabular}{|c|c|c|c|c|c|c|c|}
\hline \multirow{2}{*}{ Matrix } & \multirow{2}{*}{ Primary ion } & \multirow{2}{*}{$\begin{array}{l}\text { Primary-ion } \\
\text { current density } \\
\left(\mathrm{mA} / \mathrm{cm}^{2}\right)\end{array}$} & \multicolumn{3}{|c|}{ Detection limit (atoms $\left./ \mathrm{cm}^{3}\right)$} & \multirow{2}{*}{\multicolumn{2}{|c|}{ Ref. }} \\
\hline & & & $\mathrm{He}$ & $\mathrm{Ar}$ & $\mathrm{Kr}$ & & \\
\hline $\mathrm{Si}$ & $\mathrm{O}_{2}^{+} \quad-$ & - & $\sim 10^{18}$ & - & - & Wilson et al. & [14] \\
\hline $\mathrm{Si}$ & $\mathrm{O}_{2}^{+}(5.5 \mathrm{keV})$ & $35-40$ & - & $3 \times 10^{18}$ & - & Ray et al. & [15] \\
\hline $\mathrm{Si}$ & $\mathrm{O}_{2}^{+}(6.0 \mathrm{keV})$ & - & - & $6 \times 10^{19}$ & - & Stevie et al. & [17] \\
\hline $\mathrm{Ge}$ & $\mathrm{O}_{2}^{+}(5.5 \mathrm{keV})$ & $35-40$ & - & $7 \times 10^{18}$ & $2 \times 10^{18}$ & Ray et al. & [15] \\
\hline GaAs & $\mathrm{O}_{2}^{+} \quad-$ & - & $\sim 10^{18}$ & - & - & Wilson et al. & [14] \\
\hline GaAs & $\mathrm{O}_{2}^{+}(5.5 \mathrm{keV})$ & $35-40$ & - & $2 \times 10^{18}$ & $\sim 10^{19}$ & Ray et al. & [15] \\
\hline $\mathrm{Si}$ & $\mathrm{Cs}^{+}(8.0 \mathrm{keV})$ & 6 & - & $2 \times 10^{18}$ & $6 \times 10^{18}$ & Ray et al. & [15] \\
\hline $\mathrm{Si}$ & $\mathrm{Cs}^{+}(5.5 \mathrm{keV})$ & $0.06-0.32$ & $\sim 10^{19}$ & - & - & Gnaser, Oechsner & [16] \\
\hline $\mathrm{Ge}$ & $\mathrm{Cs}^{+}(8.0 \mathrm{keV})$ & 6 & - & $4 \times 10^{17}$ & $\sim 10^{19}$ & Ray et al. & [15] \\
\hline GaAs & $\mathrm{Cs}^{+}(8.0 \mathrm{keV})$ & 6 & - & $7 \times 10^{17}$ & $\sim 10^{19}$ & Ray et al. & [15] \\
\hline
\end{tabular}

potential can be varied between $+4375 \mathrm{~V}$ and $+4625 \mathrm{~V}$ for recording energy distributions of positive secondary ions or detecting positive secondary ions with the energy filtering technique. The primary-ion current was varied between $200 \mathrm{nA}$ and $500 \mathrm{nA}$ and the raster size between $(75 \mu \mathrm{m})^{2}$ and $(250 \mu \mathrm{m})^{2}$, namely, primary-ion current densities (ion current/raster area) ranging from 0.16 to $3.5 \mathrm{~mA} / \mathrm{cm}^{2}$. The value of the primary-ion current was monitored in the standard IMS-4f Faraday cup. Positive secondary ions of $\mathrm{M}^{+}$and $\mathrm{MCs}^{+}$produced by $\mathrm{O}_{2}{ }^{+}$and $\mathrm{Cs}^{+}$primary beams, respectively, were detected by an electron multiplier. The secondary ions were collected from the central region of the sputtered craters in order to minimize the crater edge and sidewall effects. For all depth-profiling measurements, the energy window of the kinetic energy filter of secondary ions was symmetrically opened to $55 \mathrm{eV}$ (total energy band pass of $110 \mathrm{eV}$ ). The energy window can be moved by $\pm 55 \mathrm{eV}$. The crater depth was measured with a Dektak 3030 profilometer. The conversion of ion counts (count/s) to concentration (atoms $/ \mathrm{cm}^{3}$ ) was accomplished using the relative sensitivity factors (RSFs). ${ }^{5}$ The detection limits were defined as the average background signal at the constant level measured in the tail of the implantation profile. The kinetic energy spectra of the secondary ions were determined by varying a sputtered ion accelerating potential of around $+4.5 \mathrm{kV}$ by computer control.

All measurements were performed after $15 \mathrm{~h}$ pumping after sample introduction into the sample chamber. The vacuum in the sample chamber during the measurement was $1.3-2.7 \times$ $10^{-7} \mathrm{~Pa}\left(1-2 \times 10^{-9}\right.$ Torr $)$.

\section{Results and Discussion}

\section{Energy filtering}

As a result of a SIMS analysis, it was confirmed that the $\mathrm{W}$ films contain such light elements as $\mathrm{H}, \mathrm{C}$ and $\mathrm{O}$. These light elements also exist in the SIMS sample chamber as residual gases. No other impurities were observed. Therefore, the detection of ${ }^{40} \mathrm{Ar}$ and ${ }^{40} \mathrm{Ar}^{133} \mathrm{Cs}^{+}$is influenced by the ${ }^{12} \mathrm{C}_{2}{ }^{16} \mathrm{O}^{+}$and ${ }^{12} \mathrm{C}_{2}{ }^{16} \mathrm{O}^{133} \mathrm{Cs}^{+}$mass interference molecular ions, respectively. There are two techniques used to resolve the mass interfaces: high mass resolution and energy-filtering techniques., ${ }^{5,7}$ However, a high-mass resolution technique is undesirable for routine measurements because adjusting the instrument is troublesome due to hysteresis effects. The analysis of $\mathrm{Ar}$ in $\mathrm{W}$ would require a mass resolution $(\mathrm{m} / \Delta m)$ of $\approx 1230$ for $\mathrm{Ar}^{+} / \mathrm{C}_{2} \mathrm{O}^{+}$ and $\approx 5320$ for $\mathrm{ArCs}^{+} / \mathrm{C}_{2} \mathrm{OCs}^{+}$. This mass resolving power

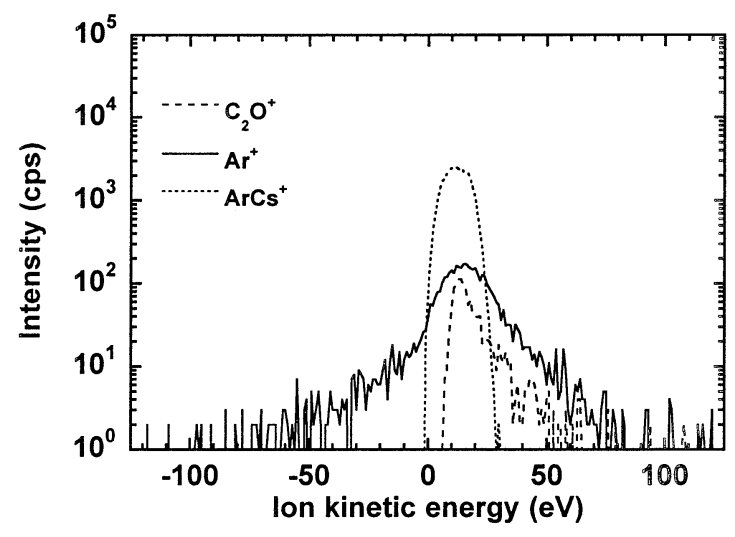

Fig. 1 Secondary-ion energy spectra for ${ }^{12} \mathrm{C}_{2} \mathrm{O}^{+},{ }^{40} \mathrm{Ar}^{+}$using an $\mathrm{O}_{2}{ }^{+}$ primary ion and ${ }^{40} \mathrm{Ar}^{133} \mathrm{Cs}^{+}$using a $\mathrm{Cs}^{+}$primary ion. The ${ }^{12} \mathrm{C}_{2} \mathrm{O}^{+}$ions were obtained from non-implanted $\mathrm{W}$ samples. $\mathrm{The}^{40} \mathrm{Ar}^{+}$and ${ }^{40} \mathrm{Ar}^{133} \mathrm{Cs}^{+}$ions were obtained from ${ }^{40} \mathrm{Ar}$ implanted $\mathrm{W}$ samples.

exceeds the capability of typical quadrupole instruments where $m / \Delta m \leq 500 .^{5}$ On the other hand, energy filtering is available when the ion kinetic-energy spectra between analyte and interface ions are different.

The sputtered species having high ionization potentials, such as rare gases, are ionized almost entirely by gas-phase ionization processes which occur in a vacuum above the sample surfaces. ${ }^{18}$ In contrast, the ionization of sputtered $\mathrm{C}$ and $\mathrm{O}$ containing contaminants would have taken place at the sample surfaces. Therefore, the $\mathrm{C}$ and $\mathrm{O}$ containing molecular ions must be suppressed by an energy-filtering technique. In order to verify the difference in the ionization mechanism between $\mathrm{Ar}^{+}$and $\mathrm{C}_{2} \mathrm{O}^{+}$sputtered from the $\mathrm{W}$, the energy spectra of these ions were examined. The results obtained with $5.5 \mathrm{keV} \mathrm{O}_{2}{ }^{+}$ primary ions are shown in Fig. 1. The energy spectrum of the $\mathrm{ArCs}^{+}$ion under $5.5 \mathrm{keV} \mathrm{Cs}{ }^{+}$bombardment is also shown in Fig. 1. In contrast to $\mathrm{C}_{2} \mathrm{O}^{+}$and $\mathrm{ArCs}^{+}, \mathrm{Ar}^{+}$ions are primarily observed on the negative-energy side in the spectrum ("prepeak ions"). The prepeak ions are ascribed to post-ionization of sputtered neutrals in the strong electric field in front of the sample. Thus, it is indicated from Fig. 1 that some of $\mathrm{Ar}^{+}$is formed by the gas-phase ionization processes, as already mentioned in Ref. 18, whereas the ionization of $\mathrm{C}_{2} \mathrm{O}$ occurs at the sample surfaces. It can be expected that suppression of $\mathrm{C}_{2} \mathrm{O}^{+}$is achieved when the energy spectra are shifted by offsetting the sample voltage so as to accept only ions where 


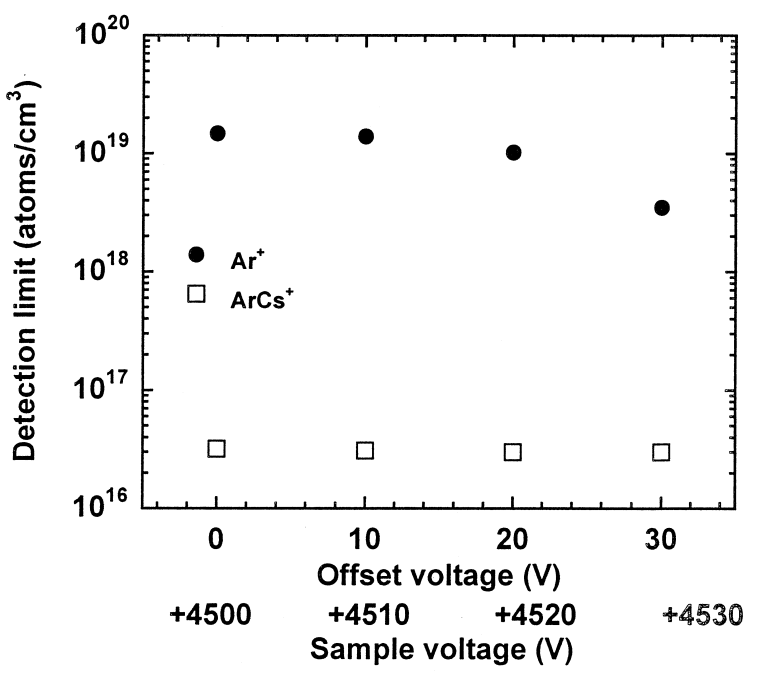

Fig. 2 Detection limits of $\mathrm{Ar}$ in $\mathrm{W}$ measured with various sample voltages, monitoring $\mathrm{Ar}^{+}(\bullet)$ and $\mathrm{ArCs}^{+}(\square)$ obtained with $\mathrm{O}_{2}{ }^{+}$and $\mathrm{Cs}^{+}$primary ion beams, respectively. The current density of both primary ions was $0.16 \mathrm{~mA} / \mathrm{cm}^{2}$.

energies lie on the low-energy side. In order to achieve the lowest detection limit of Ar, the optimum condition of energy filtering was investigated as a function of the sample voltage. The results are shown in Fig. 2. It can be seen that in comparison with the normal analytical condition, the detection limit of $\mathrm{Ar}$ monitoring $\mathrm{Ar}^{+}$is improved by a factor of 4 when the sample voltage is increased from normal $+4500 \mathrm{~V}$ to +4530 $\mathrm{V}$ under a slit width of $110 \mathrm{eV}$ in the kinetic energy filter. It was found that the energy-filtering technique for an $\mathrm{O}_{2}{ }^{+}$ bombardment analysis is useful in avoiding interference from $\mathrm{C}_{2} \mathrm{O}^{+}$ions. No further improvement of the detection limit was observed when the energy spectra were shifted by more than 30 $\mathrm{eV}$ due to a loss of the signal intensity of $\mathrm{Ar}^{+}$. Energy filtering had no effect on improving the detection limit of Ar monitoring $\mathrm{ArCs}^{+}$, because, as shown in Fig. 3, the influence of $\mathrm{C}_{2} \mathrm{OCs}^{+}$ interference ion can be negligible due to the lower background signal of $\mathrm{C}_{2} \mathrm{OCs}^{+}$. Returning Fig. 2, it can be seen that the $\mathrm{Ar}$ detection limit using $\mathrm{ArCs}^{+}$is approximately 2 orders of magnitude lower than that determined for $\mathrm{Ar}^{+}$. The reason is that, in addition to no-problem of $\mathrm{C}_{2} \mathrm{OCs}^{+}$mass interference ion, the yield of $\mathrm{ArCs}^{+}$is much more sensitive than that of $\mathrm{Ar}^{+}$, as shown in Fig. 1.

Figure 4 summarizes the $\mathrm{Ar}$ detection limits monitoring $\mathrm{Ar}^{+}$ and $\mathrm{ArCs}^{+}$, as a function of the $\mathrm{O}_{2}{ }^{+}$or $\mathrm{Cs}^{+}$primary-ion current density $\left(J_{\mathrm{O}_{2}}\right.$ or $\left.J_{\mathrm{CS}}\right)$. It is clear that there is a linear dependence of the Ar detection limit on the primary-ion current density. The correlation between the detection limit $(c)$ and the primaryion current density $\left(J_{\mathrm{O}_{2}}\right.$ or $\left.J_{\mathrm{Cs}}\right)$ can be expressed as follows: $c\left(\mathrm{Ar}^{+}\right) \propto 6 \times 10^{17} / J_{\mathrm{O}_{2}}{ }^{1.3}, c\left(\mathrm{ArCs}^{+}\right) \propto 4 \times 10^{15} / J_{\mathrm{Cs}^{1.1}}$. Increasing the primary current density by more than $J_{\mathrm{O}_{2}}=1.0 \mathrm{~mA} / \mathrm{cm}^{2}$ or $J_{\mathrm{Cs}}=3.0 \mathrm{~mA} / \mathrm{cm}^{2}$ did not result in the expected detection limit. The reason for this phenomenon would be the crater edge and sidewall effects due to a poorly focused primary beam and a small-area analysis. ${ }^{5,7,19}$

\section{Depth resolution}

Figure 5 shows examples of the Ar depth profiles in $\mathrm{W}$, obtained by monitoring $\mathrm{Ar}^{+}$with $\mathrm{O}_{2}{ }^{+}$primary-ion $\left(J_{\mathrm{O}_{2}}=0.32\right.$ $\left.\mathrm{mA} / \mathrm{cm}^{2}\right)$ and monitoring $\mathrm{ArCs}^{+}$with $\mathrm{Cs}^{+}$primary-ion $\left(J_{\mathrm{Cs}}=\right.$ $\left.0.32 \mathrm{~mA} / \mathrm{cm}^{2}\right)$. The erosion rates of $\mathrm{O}_{2}{ }^{+}$and $\mathrm{Cs}^{+}$primary-ion

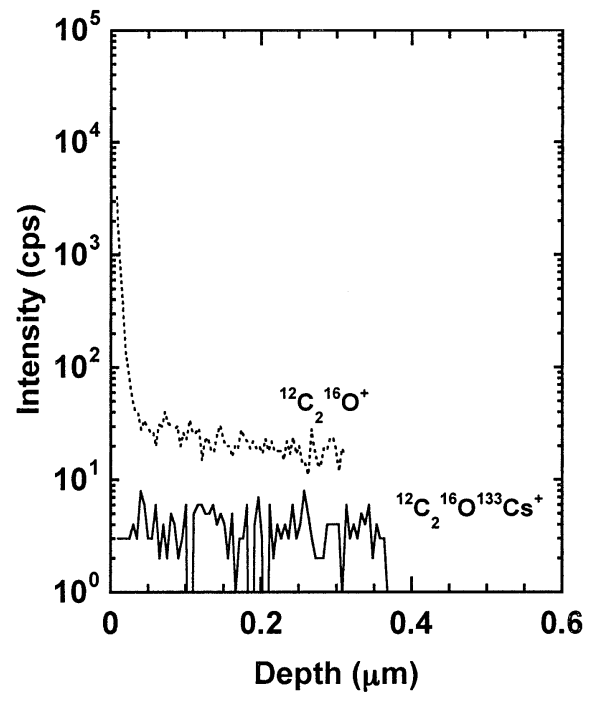

Fig. 3 SIMS depth profiles of $\mathrm{C}_{2} \mathrm{O}^{+}$and $\mathrm{C}_{2} \mathrm{OCs}^{+}$, obtained with $\mathrm{O}_{2}{ }^{+}$ and $\mathrm{Cs}^{+}$primary ion, from non-implanted $\mathrm{W}$ samples. The primaryion current density was $0.16 \mathrm{~mA} / \mathrm{cm}^{2}$.

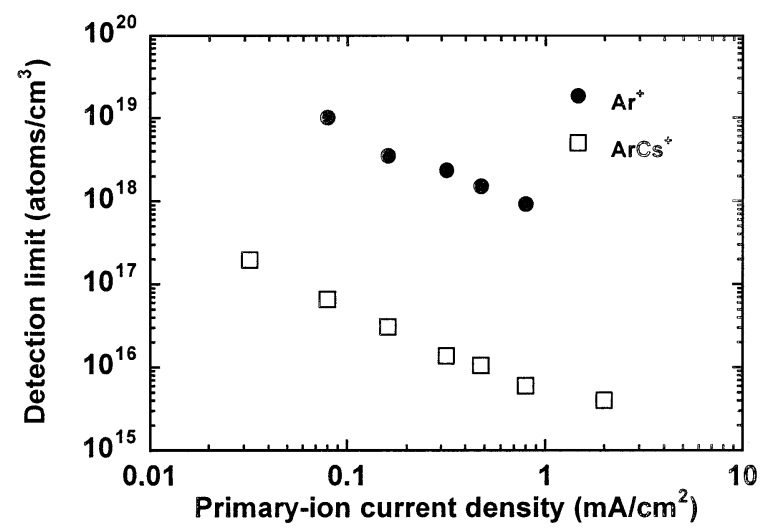

Fig. 4 Detection limits of $\mathrm{Ar}$ in $\mathrm{W}$, as a function of $\mathrm{O}_{2}{ }^{+}$or $\mathrm{Cs}^{+}$ primary-ion current density. The detected secondary ions were $\mathrm{Ar}^{+}$ (•) and $\mathrm{ArCs}^{+}(\square)$ obtained with $\mathrm{O}_{2}{ }^{+}$and $\mathrm{Cs}^{+}$primary ion beam, respectively. An offset voltage of $30 \mathrm{~V}$ (sample voltage: $+4530 \mathrm{~V}$ ) was applied for detecting $\mathrm{Ar}^{+}$.

beam measurements were $0.4 \mathrm{~nm} / \mathrm{s}$ and $1.5 \mathrm{~nm} / \mathrm{s}$, respectively. On the basis of the optimum condition discussed in the previous section, energy shifting of $30 \mathrm{eV}$ was applied in the detection of $\mathrm{Ar}^{+}$. As shown in Fig. 5, the depth resolution of the $\mathrm{Ar}^{+}$profile is worse in comparison with the $\mathrm{ArCs}^{+}$profile. It has been documented that the ion bombardment of solid surfaces produces a surface topography ${ }^{5,20-22}$ which leads to a degradation of the depth resolution. ${ }^{5}$ The surface topography of polycrystals is more pronounced than that of single crystals according to the experimental results obtained from the $\mathrm{O}_{2}{ }^{+}$bombardment of $\mathrm{Cu}^{22}$ Therefore, the result of Fig. 5 is attributed to the difference in the surface topography between $\mathrm{O}_{2}{ }^{+}$and $\mathrm{Cs}^{+}$ sputtering; the development of the $\mathrm{W}$ surface topography would be more pronounced for $\mathrm{O}_{2}{ }^{+}$than for $\mathrm{Cs}^{+}$bombardment. It is also noted that in contrast to $\mathrm{ArCs}^{+}$, the poor detection limits of $\mathrm{Ar}$ monitoring $\mathrm{Ar}^{+}$result from the inferior depth resolution of the $\mathrm{Ar}^{+}$profile. 


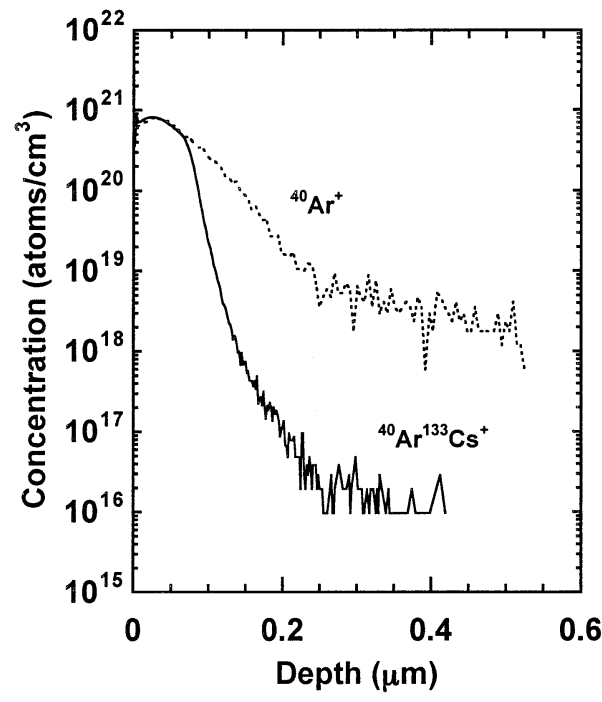

Fig. 5 SIMS depth profiles of $100 \mathrm{keV}$ Ar implanted in W Detected secondary-ions were $\mathrm{Ar}^{+}$and $\mathrm{ArCs}^{+}$obtained with $\mathrm{O}_{2}{ }^{+}$and $\mathrm{Cs}^{+}$primary-ion beam, respectively. The current density of both $\mathrm{O}_{2}{ }^{+}$ and $\mathrm{Cs}^{+}$primary-ion was $0.32 \mathrm{~mA} / \mathrm{cm}^{2}$. An offset voltage of $30 \mathrm{~V}$ (sample voltage: $+4530 \mathrm{~V}$ ) was applied for detection of $\mathrm{Ar}^{+}$.

\section{Acknowledgements}

The author would like to thank Dr. M. Schuhmacher (Cameca, Courbevoie, France) for providing a measurement method for an actual energy-band pass in the energy window. The author also acknowledges A. Murakoshi (Semiconductor Company, Toshiba Corp.) for performing Ar implantations, and Dr. H. Nakanishi for encouragement throughout this work.

\section{References}

1. A. Pan and J. E. Greene, Thin Solid Films, 1981, 78, 25.

2. J. A. Thornton and D. W. Hoffman, J. Vac. Sci. Technol. A, 1985, 3, 576.

3. V. Stambouli, O. Burat, D. Bouchier, F. Meyer, J-P. Gilles, and G. Gautherin, Thin Solid Films, 1990, 193/194, 181.

4. A. Benninghoven, F. G. Rüdenauer, and H. W. Werner,
"Secondary Ion Mass Spectrometry: Basic Concepts, Instrumental Aspects, Applications and Trends", 1987, John Wiley and Sons, New York.

5. R. G. Wilson, F. A. Stevie, and C. W. Magee, "Secondary Ion Mass Spectrometry: A Practical Handbook for Depth Profiling and Bulk Impurity Analysis", 1989, John Wiley and Sons, New York.

6. M. G. Dowsett and E. A. Clark, "Practical Surface Analysis, 2nd ed. Vol. 2: Ion and Neutral Spectroscopy", ed. D. Briggs and M. P. Seah, 1992, John Wiley and Sons, Chichester, 229.

7. P. C. Zalm, Rep. Prog. Phys., 1995, 58, 1321.

8. J. K. Nørskov and B. I. Lundqvist, Phys. Rev. B, 1979, 19, 5661.

9. M. L. Yu, Phys. Rev. Lett., 1981, 47, 1325.

10. N. D. Lang, Phys. Rev. B, 1983, 27, 2019.

11. M. L. Yu and N. D. Lang, Nucl. Instr. Meth. B, 1986, 14, 403.

12. M. L. Yu, Nucl. Instr. Meth. B, 1986, 15, 151.

13. "CRC Handbook of Chemistry and Physics", 75th ed., 1994 - 1995, CRC Press, Boca Raton.

14. R. G. Wilson, V. R. Deline, and C. G. Hopkins, Appl. Phys. Lett., 1982, 41, 929.

15. M. A. Ray, J. E. Baker, C. M. Loxton, and J. E. Greene, J. Vac. Sci. Technol. A, 1988, 6, 44.

16. H. Gnaser and H. Oechsner, Surf. Interface Anal., 1991, 17, 646.

17. F. A. Stevie, P. M. Kahora, S. Singh, and L. Kroko, in Proceedings of the Sixth International Conference on Secondary Ion Mass Spectrometry, SIMS VI, ed. A. Benninghoven, A. M. Huber, and H. W. Werner, 1988, John Wiley and Sons, Chichester, 319 - 322.

18. M. Bernheim, G. Blaise, and G. Slodzian, Int. J. Mass Spectrom. Ion Phys., 1972/73, 10293.

19. W. Vandervorst, H. E. Maes, and R. De Keersmaecker, Surf. Interface Anal., 1992, 4, 245.

20. G. Carter, B. Navinšek, and J. L. Whitton, "Topics in Applied Physics, Sputtering by Particle Bombardment II", ed. R. Behrisch, 1983, Vol. 52, Springer-Verlag, Berlin, 231.

21. F. A. Stevie, P. M. Kahora, D. S. Simons, and P. Chi, J. Vac. Sci. Technol. A, 1986, 6, 76.

22. V. Naundorf and M.-P. Macht, Nucl. Instr. Meth., 1980, $168,405$. 